\title{
THE ORIGIN OF ARCTIC PRECIPITATION AS DEDUCED FROM ITS DEUTERIUM EXCESS \\ (Abstract)
}

\author{
by \\ J. White \\ (Laboratoire de Géochimie Isotopique/LODYC, CEA/IRDI/DESICP,
} DPC-CEN Saclay, 91191 Gif sur Yvette Cédex, France)

and

\section{S.J. Johnsen and W. Dansgaard}

(Department of Glaciology, Geophysical Institute, University of Copenhagen, Haraldsgade 6, DK -2200 Copenhagen N, Denmark)

\section{ABSTRACT}

Continuous profiles of deuterium excess, $\mathrm{d}=$ $\delta D-8 \delta^{18} \mathrm{O}$, in the snow-pack have been measured at continental, high-elevation stations: Dye 3/4B ( $2480 \mathrm{~m}$ a.s.1.) in southern Greenland, and Site G $(3110 \mathrm{~m}$ a.s.1.; $70 \mathrm{~km}$ south-east of Crête) in central Greenland.

Figure 1 shows the $\delta^{18} \mathrm{O}$ and the $\mathrm{d}$ profiles along the upper $4.3 \mathrm{~m}$ of firn at Site $\mathrm{G}$. These profiles represent the snow accumulation from late 1974 to mid-1985, judging from the clear seasonality in the $\delta^{18} \mathrm{O}$ record. There is also a seasonality in the $d$ values, which generally range from +5 to $+12 \%$. In contrast to the findings at low-elevation stations, the two seasonal cycles are not in antiphase; the $d$ curve lags the $\delta^{18} \mathrm{O}$ curve by only approximately $90^{\circ}$. These same features appear when plotting similar data from Dye 3.

Modelling of the data proceeds in three steps. First, the isotopic composition of vapour evaporating from an oceanic source area is calculated on the basis of Merlivat and Jouzel's (1979) model, which takes kinetic effects into account. Secondly, the vapour is advected to the ice sheet, without mixing with vapour from other sources. Any liquid precipitation is assumed to be formed by a Rayleigh condensation process down to $-5^{\circ} \mathrm{C}$. Thirdly, the snow formation at lower temperatures is modelled, taking account of kinetic effects due to supersaturation of vapour with respect to ice (Jouzel and Merlivat 1984).

The result of this modelling is that the initial mixing ratio ( $w_{\mathrm{SO}} ; \mathrm{g} \mathrm{H} \mathrm{H}_{2} \mathrm{O} / \mathrm{kg}$ dry air; data from IAEA/WMO) largely determines the change of $\mathrm{d}$ in the precipitate as $\delta^{18} \mathrm{O}$ decreases during cooling. Furthermore, the absolute magnitude of the deuterium excess is mainly determined by the sea-surface temperature $\left(T_{s}\right)$ in the source area.

The combined result of these effects is shown in Figure 2, the upper part of which applies to a high-latitude source region (Weathership $A$ at $62^{\circ} \mathrm{N}, 34^{\circ} \mathrm{W}$ ), and the lower part to a mid-latitude source region (Weathership $\mathrm{E}$ at $\left.35^{\circ} \mathrm{N}, 48^{\circ} \mathrm{W}\right) . \mathrm{d}_{\mathrm{vo}}$ is the deuterium excess of the parent vapour as it leaves the source area; $d_{p o}$ is that of first-stage precipitation predicted by the model, and $d_{p}$ is the predicted deuterium excess in the precipitate at Site ${ }_{G}$.

In the high-latitude case, $d_{v o}$ and $d_{\text {po }}$ have pronounced summer minima and winter maxima. As the cooling proceeds (until the observed $\delta^{18} \mathrm{O}$ values at Site $\mathrm{G}$ are reached), this cycle is inverted so that at Site $G$ the model predicts maximum $d_{p}$ in August and minimum $d_{p}$ in January, and deuterium excesses on the ice sheet which are far too low (cf. Fig.1). This is true regardless of the choice of parameters for the model.

In contrast, starting with vapour from a mid-latitude source (such as the Weathership E area), the model predicts for Site $G$ a maximum in September and a minimum in March, with values of 14 and 4\%o respectively.

The latter results are in good agreement with the observations at Site G (Fig.1), and also with those at Site $4 \mathrm{~B}$, in respect of the annual mean as well as the seasonal amplitude and the phase.

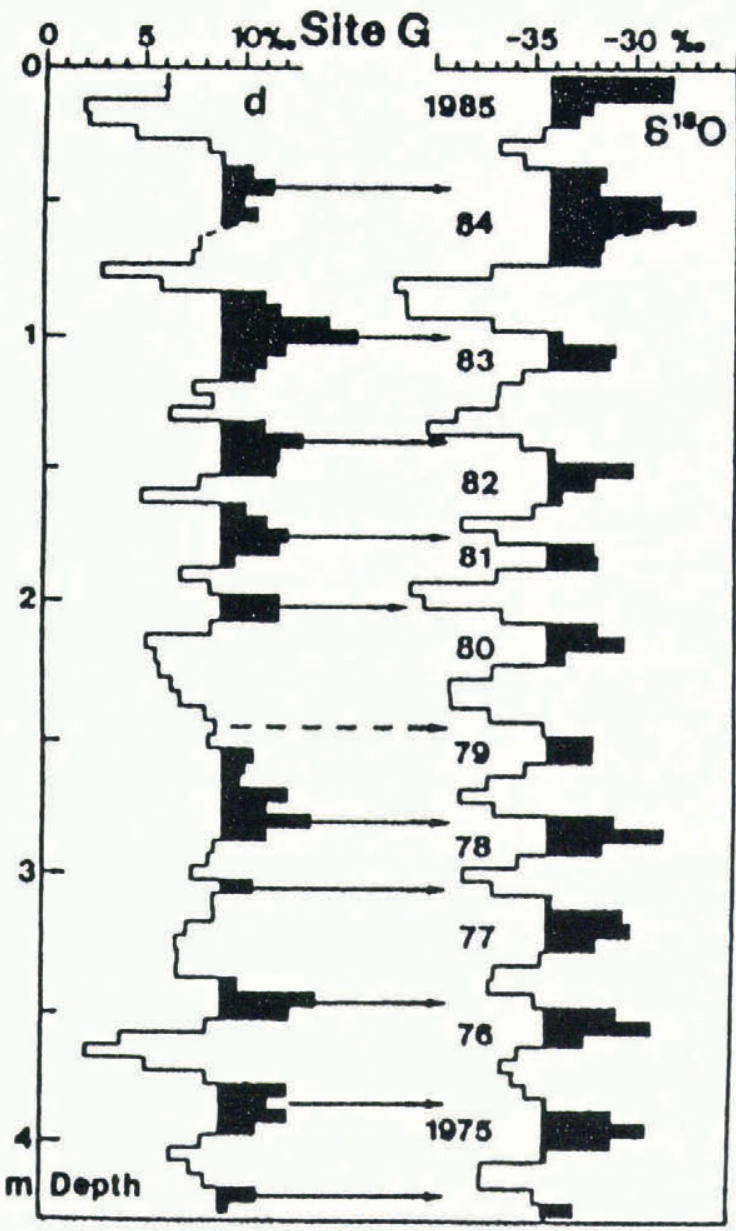

Fig.1. Deuterium excess (d) and $\delta^{18} \mathrm{O}$ profiles of the upper $4.3 \mathrm{~m}$ of firn at a high-elevation site on the Greenland ice sheet (Site $\mathrm{G} ; 71^{\circ} \mathrm{N}, 35^{\circ} \mathrm{W}$ ). 


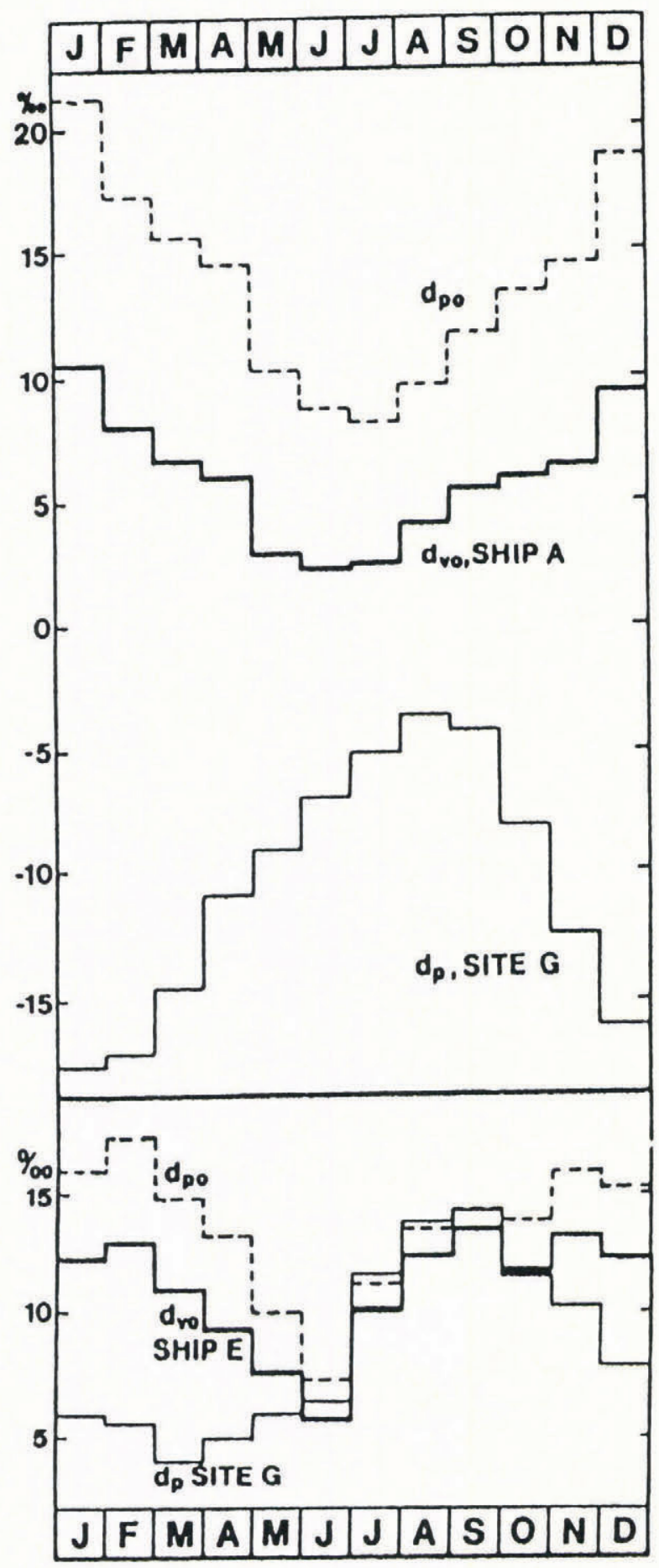

Fig.2. Calculated seasonal deuterium excess variation in parent vapour $\left(\mathrm{d}_{\mathrm{vo}}\right)$, first-stage precipitation $\left(\mathrm{d}_{\mathrm{po}}\right)$, and in snow at Site $G\left(d_{p}\right)$, assuming a high-latitude (Weathership A, top section) and a subtropical (Weathership E, bottom section) vapour source.
We conclude that, in contrast to polar low-elevation stations, the ice sheet receives precipitation from moisture which originates predominantly from much lower latitudes. The moisture has probably been carried northward at considerable altitudes by the cyclonic conveyer belts, and is thus more or less separated from the ocean surface at an early stage.

A more complete description of the model will be submitted to Tellus in the near future.

\section{ACKNOWLEDGEMENT}

This work was supported by the Danish Natural Science Research Council and the Commission for Scientific Research in Greenland. The firn samples were collected with logistic support from the U.S. National Science Foundation, Division of Polar Programs.

\section{REFERENCES}

International Atomic Energy Agency/World Meteorological Organization 1969-79 Environmental isotope data No 1-6. World survey of isotope concentration in precipitation. Vienna, I.A.E.A. (Technical Reports Series 96, 117, 129, 147,165 and 192)

Jouzel J, Merlivat L 1984 Deuterium and oxygen 18 in precipitation: modeling of the isotopic effects during snow formation. Journal of Geophysical Research 89(D7): 11749-11757

Merlivat L, Jouzel J 1979 Global climatic interpretation of the deuterium-oxygen 18 relationship for precipitation. Journal of Geophysical Research 84(C8): 5029-5033 